\title{
A Plea for the Comprehensiveness of the Category of Moral "Luck"
}

\author{
Robert Zaborowski ${ }^{1}$ (])
}

Received: 18 July 2021 / Accepted: 17 October 2021 / Published online: 10 November 2021

(c) The Author(s) 2021

\begin{abstract}
The aim of this paper is to improve our understanding of the category of moral "luck". In current debate most often only specific cases of moral "luck" are taken into account. Such restrictions, however, involving a fragmentary picture of moral "luck", are introduced without any rationale for them. In this paper I look for a formal comprehensiveness of the category of moral "luck". I consider three factors each of which is developed in two scenarios. These are (i) whether the agent's action is nasty or nice, (ii) whether the agent's intention is confirmed or contradicted by her action, and (iii) whether the agent's action is preceded by her intention or the lack thereof. I explore eight scenarios which are a mark of the intricacy of the category of moral "luck" otherwise ignored in the literature. After an assessment of their structure I arrive at new distinctions. The upshot is a rather complex set of correlations between several cases of moral "luck" with a variety of kinds and shades.
\end{abstract}

Keywords Moral "luck" · Comprehensive vs fragmentary approach · Bad luck · Good luck · Tragic error · Comic error

\section{Introduction}

It is trivial to state that the question of moral "luck" is one with a steadily growing number of contributions. The Routledge Handbook of the Philosophy and Psychology of Luck (Church and Hartman 2019) published recently, 470-page long and containing 39 chapters is an example of it. However, it is characteristic that when

\footnotetext{
1 If I use inverted commas for "luck", this is because I speak about the category, not phenomena of which I do not wish to take any position as to whether it exists or not.

Robert Zaborowski

thymos2001@yahoo.fr

1 L. \& A. Birkenmajer Institute for the History of Science, Polish Academy of Sciences, Warsaw, Poland
} 
moral "luck" is analyzed, most often, if not exclusively, ${ }^{2}$ a somehow restricted range of cases is taken into account. ${ }^{3}$ It is, rather frustratingly, just a pair of agents with no intention of harm but of which one does harm and the other not. But others, significantly different pairs of agents involved in moral "luck" can be conceived, which means that those who limit themselves to just this one opposition (as in the case of the driver) can scrutinize only a part of moral "luck" picture. In other words many analyses of the category of moral "luck" are partial or biased. Instead I believe that if the category of moral "luck" be reasonably applied, the model should be formally sound. This is why, unless an argument for a restriction is provided, which to the best of my knowledge is not the case, as many of its applications as possible should be analyzed. This is what I intend to do. The outcome is that the category of moral "luck" offers paradoxes which are most often left unnoticed when only a part of the picture is explored. Paradoxes, which reveal the very structure of the category, call for a better formalisation of the category of moral "luck".

\section{Towards Formal Comprehensiveness}

\subsection{Presenting the Picture}

\subsubsection{Comprehensiveness Over Fragmentariness}

As said, unless an argument for the fragmentariness of the category is overtly stipulated and argued for, the category should be regarded comprehensively. This means that all relevant examples should be taken into account. To use the recurrent example of the driver: not only the pair of the driver who killed a pedestrian versus the driver who did not kill a pedestrian, or only the pair of the reckless driver versus the prudent driver should be analyzed, as is the case. Instead, they should all be considered together. The reason is that, for instance, if we call a prudent driver who killed a pedestrian unlucky, then the one who did not kill should be called lucky, unless we want to claim that not killing the pedestrian by the prudent driver does not involve luck, while the alternative scenario does. The latter might be claimed only, it seems to me, if we believe that the prudent driver necessarily and unavoidably does not kill a pedestrian. But such a belief is nonsense as soon as we accept that the prudent driver may-even if unluckily-kill a pedestrian. If so, it is reasonable to call the prudent driver who killed the pedestrian unlucky and the prudent driver who did not kill the pedestrian lucky.

What about the reckless driver who killed and the reckless driver who did not kill the pedestrian? If we call the latter lucky, the former should be called unlucky, unless one suggests that being reckless necessarily and unavoidably entails killing a pedestrian. As the discussion shows, even the driver with an intention to kill a

\footnotetext{
2 See Enoch 2019, 2, n. 7: "Everyone uses some version of a driver example [...]". The example is Williams' $(1976,124)$ and has been first taken up by Nagel in his response to Williams 1976, 140-141.

3 See several chapters in Church and Hartman (2019).
} 
pedestrian does not kill her necessarily and unavoidably. ${ }^{4}$ If so, this applies to an even higher degree to the driver with no intention to kill a pedestrian. If things stand this way, we get the following: the two drivers who killed are unlucky, while the two drivers who did not are lucky. Something puzzling, however, emerges: there is a manifest difference, all things being equal, ${ }^{5}$ between the two drivers who killed and also between the two others who did not. Neither had an intention to kill, but the one who was reckless and did not kill seems more lucky than the prudent one who did not kill a pedestrian. This is so because prudence while driving is specifically intended to avoid such situations as killing the pedestrian and for this reason being prudent is typically recommended to drivers. Accordingly, if the prudent driver did not kill, there is nothing anomalous or unexpected about it, as it is with the prudent driver who did on the one hand and with the reckless driver who did not on the other. By the same token, it seems not anomalous or unexpected to see the reckless driver who killed a pedestrian.

Now, being prudent, like being reckless, is a matter of degree. This is why I would say that a somehow reckless driver who did not kill the pedestrian is less lucky than a consistently reckless driver who did not and a somewhat reckless driver who killed the pedestrian is more unlucky than a consistently reckless driver who did. And this is why the prudent driver who killed-other things being equal-seems the most unlucky. As for the prudent one who did not kill it may seem uncommon to call her lucky. If however we realize that being prudent and killing are not exclusive, calling the prudent driver who did not kill lucky is correct. Hence I would, for the sake of consistency, call her lucky although less lucky than the one who was reckless and did not kill. Now, being lucky or unlucky is also a matter of degree: of the two drivers the one who takes more precautions to avoid killing is more unlucky, if she happens to kill. ${ }^{6}$

\subsubsection{A Better Setting}

As good as it is, we have arrived at 4 scenarios and although this is better than only initial two this is still not the whole picture. We should now include into moral "luck" picture the pair of the driver causing a fatal accident versus the driver who rescues a pedestrian, and also the pair of the driver whose conduct confirms her

\footnotetext{
${ }^{4}$ If the driver has had an intention to kill a pedestrian, she would have been a (would-be) murderer, not a reckless driver. Unfortunately, in the discussions the driver's intention is expressed negatively, i.e. not having an intention to kill, without specifying it positively. On a possible ambiguity linked to the negative way of expressing the agent's intention see below.

${ }^{5}$ For the sake of clarity it should be added that all four drivers drove slowly, the car's brakes were correct etc. etc. There is however one difference between the prudent drivers' situation and the reckless drivers' situation: while the prudent one could not do anything more to avoid killing when the child appeared on her way out of nowhere, the reckless driver is supposed to have done not enough to avoid it in virtue of her reckless way of driving. This means that her situation was remediable, while the situation of the prudent driver was not. This makes that their situation are not exactly the same.

${ }^{6}$ If this is correct, we probably should think that there are as many degrees of bad or good luck as there are of recklessness and prudence. If someone admits that both recklessness and prudence manifest themselves in action by means of a number of several factors, then the picture of gradualness will be even more nuanced.
} 
intention versus the driver whose conduct contradicts her intention. Since killing a pedestrian, either by the reckless or by the prudent driver is unlucky, even if to a different degree, and not killing a pedestrian, either by a reckless or by the prudent driver, is lucky, even if to a different degree, in what follows I will omit the difference between a reckless and a prudent agent and I will focus instead on whether the result of the agent's act confirms her intention or contradicts it. I take it that in particular act the agent's character is instantiated by her intention. Accordingly, a reckless agent on a particular occasion may act in a prudent way and, if that happens, her very act should be accounted in the light of her prudent intention, regardless of her otherwise reckless trait. A fine example of this is Jimmy-after Nelkin (2019)-who "promised his spouse to stop eating at the local McDonald's. But were he to drive by it while it is open, he would [freely] succumb to temptation and break his promise. He avoids driving by the McDonald's so as not to break his promise." Nelkin concludes: "Surely Jimmy is not as blameworthy as he would have been, if he had driven by the McDonald's and broken his promise." But is he blameworthy at all? And if so, why? Jimmy cares about his not succumbing to temptation and not breaking his promise and as such he is a better sort of person that another who does not care. This is exactly in concocting such kind of prosthesis that Jimmy is on the right track towards virtue insofar as he will be given a corresponding character. ${ }^{7}$

Now, since a situation in which the driver, either reckless or prudent, whose conduct, either contradicting or confirming her intention, rescues a pedestrian may seem a bit far-fetched and certainly occurs much less frequently ${ }^{8}$ than a situation in which the driver, either reckless or prudent, whose conduct, either contradicting or confirming her intention, causes a fatal accident, I need a more convenient setting. To make the analysis more handy in view of the comprehensiveness of the category of moral "luck" I will employ Nagel's example about an officer in a concentration camp versus someone who left Germany in 1930. I will use it to obtain a full panorama of scenarios sharing the common denominator. Here is Nagel's:

Someone who was an officer in a concentration camp might have led a quiet and harmless life if the Nazis had never come to power in Germany. And someone who led a quiet and harmless life in Argentina might have become an officer in a concentration camp if he had not left Germany for business reasons in 1930. [...] Ordinary citizens of Nazi Germany had an opportunity to behave heroically by opposing the regime. They also had an opportunity to behave badly, and most of them are culpable for having failed this test. (Nagel 1979, 26 and 34)

I take the example with a stress on the second passage rather than on the first one, because in the second passage, unlike in the first (absent in Nagel 1976 and added

\footnotetext{
7 On not caring and shaping a character by activities see Aristotle, EN 1114a.

8 If this is true, it may contribute to explaining why there is a tendency to abandon a full symmetry. But it may be the other way round: a lucky rescuing may happen as often as an unlucky fatal accident, but people are more ready to notice what goes wrongly.
} 
in Nagel 1979), ${ }^{9}$ Nagel considers both a heroic as well as a bad behaviour. ${ }^{10}$ I do so because it opens the door to analyzing three aspects, each in the two resulting scenarios. Nagel-in the second passage in the quotation-considers, along with those who behaved badly, those who behaved heroically. Alas, in the next sentence of his paper he goes on to speak only about those who "would have behaved as badly as the Germans in like circumstances" (Nagel 1976, 146= Nagel 1979, 34), which means that he abandons the symmetrical and comprehensive analysis of the category of moral "luck". We may certainly agree with Nagel that "it is a test to which the citizens of other countries were not subjected, with the result that even if they, or some of them, would have behaved as badly as the Germans in like circumstances, they simply did not and therefore are not similarly culpable" (Nagel 1976, 146= Nagel 1979, 34). Yet the main point is that, as he says above, it was also a test for (their) heroism. If so, anything like Nazi Germany is a much larger test than the driver case.

Therefore I consider the following pairs of scenarios depending on three factors, which are (i) whether the agent's action is nasty or nice, (ii) whether the agent's intention is confirmed or contradicted by her action, and (iii) whether the agent's action is preceded by her intention or no intention:

(i) the agent intending and/or committing an awful thing versus the agent intending and/or committing a heroic thing-for lack of a better term, I call them, respectively, the nasty and the nice side of luck, ${ }^{11}$

(ii) the agent's intention being confirmed by the result of her acting versus the agent's intention being contradicted by the result of her acting-this is required because intention alone does not necessarily and unavoidably warrant the result,

(iii) finally, the agent intending to commit either an awful thing or a heroic thing versus the agent not intending to commit either an awful thing or a heroic

\footnotetext{
${ }^{9}$ Whereas Nagel 1979, 34=Nagel 1976, 145-146. The fact that Nagel added a paragraph in which behaving heroically versus behaving badly is abandoned and he discusses only behaving badly is an example of dealing with moral "luck" in a partial way. But this approach become standard, see e.g. Latus (no date), who commenting on Nagel, develops, as frequently, only the nasty side of luck: "Suppose that the expatriate would have behaved just as badly as the German if he had remained in Germany. [...]" Apart from being asymmetrical, this is too vague. I think that the comparans should be qualified, say, in such way: "... as badly as the German who behaved badly ..." for not every German behaved badly. Also a second element of symmetry should be added ("[s]uppose ... and that the expatriate would have behaved just as well as the German who behaved well if he had remained in Germany"), unless it is proved that bad luck is of significantly higher probability than good luck.

${ }^{10}$ In moral "luck" debate asymmetry involves fragmentariness. I see no reason why asymmetry should be preferred over symmetry. Asymmetry may be coming from legal practice in which there is more about punishing than about rewarding. It may be derivative of a thought that, say, giving a person a meal is not a deed as much noble as depriving a person of a meal is an ignoble deed, although the quantity of food in both cases is the same. In moral luck debate when there is a question of the Asymmetry View, it is about praise and blame and not the agent's act's actual value (see Hartman 2019).

${ }^{11}$ For one anonymous reviewer "[t]he criteria "obnoxious luck" and "innocuous luck" are not clear" and they "do not help to dispel the confusion". I appreciate this remark. To stress even more the opposition of two I replace obnoxious with nasty and innocuous with nice. I want also to emphasize that these are merely provisionary labels, not criteria. They are used to call in anyway whatsoever the members of two groups of moral "luck", but no argument depends on these labels.
} 
thing-this needs be considered because not only an agent may not complete what she intended to do, but also she may commit what she did not intend to.

The outcome is the 8 following scenarios:

a. An agent remained in Germany, she intended to commit awful things and committed awful things,

b. An agent left Germany and did not commit awful things (there), but if she had remained in Germany, she would have intended to commit awful things and she would have committed them,

c. An agent remained in Germany and committed awful things although she did not intend to commit them,

d. An agent left Germany and did not commit awful things (there) and if she had remained, she would have not intended to commit awful things and she would not have committed them,

e. An agent remained in Germany, she intended to accomplish heroic things and accomplished heroic things,

f. An agent left Germany and did not accomplish heroic things (there), but if she had remained in Germany, she would have intended to accomplish heroic things and she would have accomplished them,

g. An agent remained in Germany and accomplished heroic things although she did not intend to accomplish them),

h. An agent left Germany and did not accomplish heroic things (there) and if she had remained, she would have not intended to accomplish heroic things and she would not have accomplished them. ${ }^{12}$

One remark. If one insists on a separate analysis conducted for a reckless and a prudent agent, then 16 scenarios will obtain, and if each of four kinds of luck (after Nagel 1979, 28) ${ }^{13}$ be considered separately, then 64 scenarios will obtain, eventually if the distinction between the intrinsic and extrinsic type of luck (after Williams $1976,121-122$ ) comes in force, a total of 128 scenarios will obtain. ${ }^{14}$

\footnotetext{
12 One anonymous reviewer remarked that "the passage from the three types of pairs of scenarios to the eight scenarios is not clearly explained since in the eight scenarios new circumstances appear (such as staying or leaving Germany)". The scenarios $a$ - $h$ are based on Nagel's examples and my own below ((1)-(8)) do not contain this new element. Alternatively I could answer that staying or leaving Germany is necessary for the agent to, respectively, have an intention or no intention and as such is incorporated into it. Although it is syntactically correct to speak about, for instance, an agent who left Germany and intended to commit awful things, no awful things would be committed by her in Germany as long as she would not come back to Germany. Using a proxy may be dismissed for obvious reasons.

13 Although with the exception of constitutive luck Nagel did not use the terminology as it is known today. On the terminology see Latus (no date).

14 I limit myself to 8 scenarios because none of the three distinctions mentioned here modifies my analysis of the "luck" picture significantly in view of its formal comprehensiveness. For an attempt of rectification in view of 2 additional scenarios (*) and 4 complementary formulations (') see below.
} 


\subsubsection{A Problem}

At this point one may ask how it is possible to speculate about what an agent would have intended and if her intention would have been contradicted or confirmed by the result of her action. As a matter of fact, much of the debate on moral "luck" focuses on judgment, and on praise versus blame. Since judgment and praise versus blame depend significantly on the psychology of her who makes the assessment and also are subject to the epistemic problem, I suggest to regard not how an agent is assessed or how she feels about herself but, instead, what value she actually represents if she is an agent as described in $a-h$. In other words I suggest to focus on the way the relation-itself affected by moral "luck"-of intention of an action and the result thereof affects the value of the agent. Hence the question is not: is the agent assessed differently in all 8 scenarios?, but: is the agent's value different in all 8 scenarios? I think this makes the category of moral "luck" more stable and, therefore, analyzable. For, if we agree that "[m]oral luck occurs when factors beyond an agent's control positively affect the degree of praise or blame she deserves" (Hartman 2018, 3179) only and not the value of the agent, then we should think the latter is all about the agent's intention, not to mention the psychology and sociology of praise and blame. But then the two agents of the same pair- $a-b, c-d, e-f, g-h-$ that is one of whom completes what she intends to do while the other does not, would be of the same value. I do not think this is accurate. Consequently, since I am interested not in the structure and dynamic of moral assessment, let alone of legal judgment, ${ }^{15}$ of the agent for a particular action but in how the relation of the intention of an action and the result thereof affects the value of the agents, I leave aside a question how, if at all, it may be known what an agent would have intended and whether her intention would have been contradicted or confirmed by the result of her action. ${ }^{16}$ In such context the epistemic argument no longer presents a major problem. ${ }^{17}$ Alternatively let us admit that there are only sincere people ${ }^{18}$ in the world so that there is no more "epistemic difference" (Latus, no date) between a person who actually acted and another one who only avers what her intention would (have) be(en).

\footnotetext{
15 Nagel 1976, 146= Nagel 1979, 34 clearly states: "We judge people for what they actually do or fail to do, not just for what they would have done if circumstances had been different".

${ }^{16}$ A moral or rather, as it happens, a psychological assessment of an agent is an entirely different issue which I cannot explore here. That the way in which an agent is assessed is, or often happens to be, of psychological nature is recognized, albeit in implicit way, by Richards (1986) who speaks about "response" (198, 200 etc.), "feelings", and "reactions" (208).

17 Which requires her ability to do so, knowledge of her intention etc. I omit all this complications here since I think it may be reasonably assumed that there is an agent able to do so, knowing her intention etc.

18 The same applies if one thinks about a world in which people's thoughts may be known to the external observer. It seems the following was based on such insight: "[a] man who strangled his wife during a nightmare in the belief he was attacking an intruder walked free from court yesterday after the case against him was withdrawn. [...] psychiatrists for the prosecution and the defence agreed that he suffered from a long-standing sleep disorder and he had been in a state of automatism at the time." (Stone 2009). However, whether they were correct may be questionable.
} 


\subsubsection{A Further Analysis}

Taken together, the full panorama of scenarios $a-h$ may be represented by $1-8$, respectively, as follows:

\begin{tabular}{|c|c|}
\hline The nasty side of "luck" & The nice side of "luck" \\
\hline$A$ intends to harm and harms $O$ & $A$ intends to help and helps $O$ \\
\hline$A$ intends to harm and does not harm $O$ & $A$ intends to help and does not help $O$ \\
\hline$A$ does not intend to harm and harms $O$ & $A$ does not intend to help and helps $O$ \\
\hline$A$ does not intend to harm and does not harm $O$ & $A$ does not intend to help and does not help $O$ \\
\hline
\end{tabular}

In one important feature (1), (4), (5), and (8) visibly differ from (2), (3), (6), and (7). While in the former scenarios there is a concord between the intention of the agent $(A)$ and the result of her action towards the object $(O)$ of this action, in the latter there is none. In this sense the former is a group of successful actions and the latter-of unsuccessful ones. This could exclude the former from the discussion about moral "luck". However, I include them because they are not completely devoid of moral "luck" insofar as intention alone does not necessarily and unavoidably warrant the result. If this is correct and they are affected, even if only slightly, by moral "luck", this is enough to include them in the picture, especially if it is meant to be comprehensive.

Cases (4) and (8) are inserted for the sake of comprehensiveness of the moral "luck" picture. They are subjected to moral "luck" in the same sense as (1) and (5) because not intending to harm or help does not warrant necessarily and unavoidably, respectively, not harming or not helping. However, there is a sense in which (4) and (8) should not be included under the labels of the nasty side and the nice side of "luck". Since there is, respectively, no harm and no help resulting from the agent's action, they are neutral as long as no harm does not stand for help and, inversely, no help does not stand for harm. This stipulation is required to exclude that (4) allows for (5) and (7) and (8) allows for (1) and (3). ${ }^{19}$

Now, one may retort that the panorama presented in the above Table is not complete, for there are more scenarios and formulations, especially for cases in which intention $\neq$ result. As for the scenarios, one may superimpose on the scenarios (2) and (6), scenarios ( $\left.2^{*}\right)$ : $A$ intends to harm and (does not harm but) helps $O$, and (6*): $A$ intends to help and (does not help but) harms $O$. As for the formulations one may want to avoid in the four scenarios ((3), (4), (7), and (8)) a negative formula containing the lack of intention of $f$-ing and replace it by a positive one containing the intention of not $f$-ing ( $=$ of avoiding $f$-ing). Therefore, let (3) be replaced with (3') $A$ does intend to not harm and harms $O$, (7) with (7') $A$ does intend to not help and helps $O$, and also (4) with (4') $A$ does intend to not harm and does not harm $O$ and,

\footnotetext{
19 But one may like to think about Mixed scenarios: (3) + (7) $A$ does not intend to harm and helps $O$ versus (7) + (3) $A$ does not intend to help and harms $O$. They are both about lack of intention of f-ing followed by result identical to -(f-ing). A similar stipulation is not required for (2) and (6) because the agent's intention is positively expressed. On complications produced by a negative expression of intention see below.
} 
to end, (8) with (8') A does intend to not help and does not help $O$. Consequently, an improved Table should be offered, with additional scenarios $(*)$, and complementary formulations (') as follows:

\begin{tabular}{llll}
\hline The nasty side of "luck" & The nice side of "luck" \\
\hline 1 & $A$ intends to harm and harms $O$ & 5 & $A$ intends to help and helps $O$ \\
2 & $A$ intends to harm and doesn't harm $O$ & 6 & $A$ intends to help and doesn't help $O$ \\
$2^{*}$ & $A$ intends to harm and helps $O$ & $6^{*}$ & $A$ intends to help and harms $O$ \\
3 & $A$ does not intend to harm and harms $O$ & 7 & $A$ does not intend to help and helps $O$ \\
3 & A does intend to $n o t$ harm and harms $O$ & 7 & $A$ does intend to not help and helps $O$ \\
4 & $A$ does not intend to harm and doesn't harm $O$ & 8 & $A$ does not intend to help and doesn't help $O$ \\
4 & $A$ does intend to not harm and does not harm $O$ & $8^{\prime}$ & $A$ does intend to not help and does not help $O$ \\
\hline
\end{tabular}

Though the Table is now more enlarged, it seems that the four formulations hardly change anything. ${ }^{20}$ For not intending to harm/help and not/harming/helping and intending not to harm/help and not/harming/helping are formally similar insofar as they are both about the result of the agent's action not corresponding to her intention, that is about a harmful/helpful result which contradicts the agent's intention. The difference relies on how strongly her intention is expressed: negatively or positively (let call the former a weak opposition between the intention and the result and the latter a strong one). Although the latter seems stronger insofar as it expresses positive will, and the tension between the intention and the result is bigger, in the cases of moral "luck" it does not matter whether an agent does not intend to harm/ help or, rather, does intend not to harm/help as long as she harms/helps. For both formulations the ascription of bad "luck" and good "luck" is the same. In fact, both, (3) and (3') as well as (7) and (7'), respectively, are about the same. While the former are about bad "luck" both for the agent and the object, the latter two are about good "luck" for the object of the agent's action but not so for the agent. ${ }^{21}$

As for the scenarios $\left(2^{*}\right)$ and $\left(6^{*}\right)$, unless I am mistaken, there is one important corollary of the enlargement which is that not only is the positive intention not followed by a corresponding result (that is an action of which the agent has an intention) but, also, that the positive intention is followed by a contradictory positive result. Although there is no difference between (2) and (2*) and (6) and ( $\left.6^{*}\right)$ insofar as they all are about the agent's intention being contradicted by the results and there is none either as for their being good "luck" or bad "luck" for the agent and the object (see below 2.2.3.), their contents differ because it is one thing not to harm/ help and another to help/harm. In a word, the result goes much further than simply not completing the intention for it is in stark opposition to it. Another point to be mentioned is that $\left(2^{*}\right)$ and $\left(6^{*}\right)$ introduce an opposite element to the nasty and the nice side of "luck" respectively, with, respectively, help and harm, which makes listing them under these labels open to question.

\footnotetext{
That this is but an appearance see below.

${ }^{21}$ In the case of $(4) /\left(4^{\prime}\right)$ and $(8) /\left(8^{\prime}\right)$ where the result of the agent's action corresponds to her intention the difference in formulation is even more negligible.
} 
Before I pass on to the discussion let me indicate that the above scenarios may be still further enriched. The eight modalities could be further complicated by adding an objective factor: taking a risk. ${ }^{22}$ Take for instance (3), i.e. an agent does not intend to harm and harms. It may be divided into two subclasses: (3.1) i.e. an agent does not intend to harm, but she takes the risk of harming and harms and (3.2) i.e. an agent does not intend to harm and she does not take the risk of harming, but harms nonetheless. We may offer also two scenarios of the kind: an agent does not intend to harm, but she takes the risk of harming, but does not harm on the one hand and an agent does not intend to harm and she does not take the risk of harming and does not harm, on the other. They should be put under (4) as, respectively (4.1) and (4.2). ${ }^{23}$ This is where one could think that the crucial factor in effectuating harming or not harming is taking or not taking a risk. But this is not correct because in (2) (i.e. an agent intends to harm and does not harm), since there is an intention, risk is taken, yet there is no intended result.

\subsection{Discussion}

\subsubsection{A General Remark}

There are various correspondences between the 8 scenarios in view of the similar formal features of their structure:

(i) in (1) and (5) the result corresponds to the intention and (4)/(4') and (8)/(8') mirror them negatively.

(ii) in (2)/(2*) and (6)/(6*) intention of doing is not accomplished and (3)/(3') and $(7) /\left(7^{\prime}\right)$ mirror them negatively: in all there is a gap between what is intended and what is achieved; since in $(2) /\left(2^{*}\right)$ and $(6) /\left(6^{*}\right)$ the intention is not followed by the result and in (3)/(3') and (7)/(7') the result goes further than the intention, let us call $(2) /\left(2^{*}\right)$ and $(6) /\left(6^{*}\right)$ reluctant scenarios and $(3) /\left(3^{\prime}\right)$ and $(7) /\left(7^{\prime}\right)$ eager scenarios. Or maybe $\left(2^{*}\right)$ and $\left(6^{*}\right)$ should be called inversely eager.

\subsubsection{Horizontal vs Vertical Formal Symmetry}

Now the extent of the formal symmetry may be better fleshed out even further. There is a full formal horizontal symmetry ((1) vs (5), (2) vs (6), (2*) vs (6*) and so on) but no full formal vertical symmetry: there are (1) vs (4), (5) vs (8), (2) vs (3), (5) vs (6), (3') vs (4') and (7') vs (8'), but nothing corresponds to $\left(2^{*}\right)$ and $\left(6^{*}\right)$.

\footnotetext{
22 Again, if risk is a matter of degree, the same will be valid for the resulting scenarios.

23 Many will agree that (3.2) is an actual example of bad luck. But if so, and if such a thing as (3.2) represents bad luck par excellence, is not (4.1) an occurrence of good luck par excellence? But if it is, it is surely not good luck in the same sense as (4.2) is. And, similarly, (3.2) is not bad luck in the same sense as (3.1) is. Likewise, risk may be considered in other scenarios, esp. (7) and (8).
} 


\subsubsection{Assessing the Structure of the Eight Scenarios}

As it is presented now we have eight principal scenarios of which two exists in two variants and for four other two formulations are possible. However a following proviso should be added. All scenarios may be regarded either from the perspective of the agent or from the point of view of the object of the agent's action, i.e. the person harmed (or unharmed) or helped (or unhelped). For instance, from the point of view of the object of the agent's action (2) and (6) are not on the nasty side and on the nice side of "luck" respectively. Since the object of the agent's action is not, respectively, harmed and helped in these scenarios, they could be labelled inversely, that is, (2) as the nice side and (6) as the nasty side. In a word, the agent and the object of her action are lucky or unlucky in a different way. ${ }^{24}$ For the agent the point at issue is about completing her intention, while for the object of the agent's action the point is whether it is helpful or harmful for her. Hence for the agent the result=her intention equals good luck $(g)$, the result $\neq$ her intention equals bad luck $(b)$, and for the agent if she is harmed, this is bad luck (b), if helped, then good luck $(g)$, if neither, then neither (=neutral) ( 0$).^{25}$ The assessment of the scenarios in view of the combined agent-cum-object perspective seems therefore to run as follows: ${ }^{26}$

1. harmful intention + harmful result $g-b$

$2+2 *$. harmful intention + no harmful result/helpful result $b-g$.

$3+3$ '. no harmful intention/intention of not harming + harmful result $b-b$.

$4+4$ '. no harmful intention/intention of not harming + no result ${ }^{27} g-0$.

5. helpful intention + helpful result $g-g$

$6+6^{*}$. helpful intention + no helpful result/harmful result $b-b$.

$7+7$ '. no helpful intention/intention of not helping + helpful result $b-g$.

$8+8$. no helpful intention/intention of not helping + no result ${ }^{28} g-0$.

An interesting phenomenon becomes apparent. There are $4 \times b$ and $4 \times g$ on the agent side and $3 \times b$ and $3 \times$ g-plus $2 \times g O-$ on the object side. This is a mark of a full non-formal ${ }^{29}$ symmetry. However, this full non-formal symmetry works only for either part of every single formula, because when we pass to the entire formula of

\footnotetext{
${ }^{24}$ I take the agent and the object of her action to be two separate persons. But it does not have to be so: one may be the object of her own action of self-harming, self-helping, both intentionally and accidentally etc. Alas, I cannot go into that here.

${ }^{25}$ I take being helped/harmed in a subjective way such that if, roughly speaking, the object of the agent's action wishes to be harmed and is harmed, this will be understood as a helpful action and inversely.

${ }^{26}$ To illustrate how much the agent's intention-result divergence may influence whether the object is lucky or unlucky think about the desert traveller case (after Sartorio 2019).

${ }^{27}$ Remember the stipulation about no harm not standing for help. Hence no result means here: neither harm nor help.

${ }^{28}$ Remember the stipulation about no help not standing for harm. Hence no result means here: neither help nor harm.

${ }^{29}$ I use non-formal as it is by Frings and Funk in Scheler 1973, xv: "Unfortunately, there is no adjective form for content in English [...] the German material is used in this work as the antonym of formal $[\ldots] "$.
} 
each scenario-agent-cum-object-something different occurs. There is no symmetry anymore ${ }^{30}$ since what we have are: twice $b-b$ but once $g-g$, twice $b-g$ but once $g-b$, and twice $g-0$. This means that the agent's and the object's being lucky or unlucky coincide fully in only 3 scenarios. But there is more. If one asks whether the scenarios can be reduced to one-valued assessment, the answer is, again, complex. The reduction can be made for the cases where the two values are in accord, i.e. (3)/( $\left.3^{*}\right)$, (5), and (6)/(6*) which are, respectively, bad "luck", good "luck", and bad "luck". Maybe we can do the same for the cases where one value is neutral and assess (4)/ $(4$ ') as (weak?) good "luck" and (8)/(8') as (weak?) good "luck". For the remaining three scenarios the assessment must be two-valued (twice $b-g$, once $g-b$ ).

\subsubsection{Non-Formal Assessment of the Eight Scenarios}

What about non-formal assessment? This is where, it seems, the intricacy of the category "luck" and the difficulty of keeping it consistent become even more visible. The point is that $(2) /\left(2^{*}\right)$ should be given the same moral "luck" value as $(6) /\left(6^{*}\right)$ and $(3) /\left(3^{\prime}\right)$ as $(7) /\left(7^{\prime}\right)$ for the reason that (1) is given the same moral "luck" value as (5) and (4)/(4') the same as $(8) /\left(8^{\prime}\right)$. This is because there is no reason to assign them a different moral "luck" value unless one thinks that $(2) /\left(2^{*}\right)$ together with (3)/(3') should be accounted in view of intentions only and $(6) /\left(6^{*}\right)$ together with $(7) /\left(7^{\prime}\right)$ only in view of the results. But why should the nasty side and the nice side be accounted differently? If no reason is given, we should opt for the same basis. Consequently, for instance, if $(2) /\left(2^{*}\right)$ is morally blameworthy, $(6) /\left(6^{*}\right)$ is morally praiseworthy. But if $(6) /\left(6^{*}\right)$ is praiseworthy, then $(7) /\left(7^{\prime}\right)$ is not praiseworthy. And if $(7) /\left(7^{\prime}\right)$ is not praiseworthy, then $(3) /\left(3^{\prime}\right)$ is not blameworthy. One may prefer to claim that $(3) /\left(3^{\prime}\right)$ is blameworthy, but then, on pain of contradiction, $(7) /\left(7^{\prime}\right)$ must be praiseworthy and then, consequently, (6)/(6*) is not praiseworthy as much as (2)/ $\left(2^{*}\right)$ is not blameworthy. One may go this way given $\left(2^{*}\right)$ and $\left(6^{*}\right)$, the only two scenarios I called inversely eager, are hardly blameworthy and praiseworthy, respectively, because of help/harm done. Alternatively, either $(2) /\left(2^{*}\right)$ and $(3) /\left(3^{\prime}\right)$ are blameworthy, while $(6) /\left(6^{*}\right)$ and $(7) /\left(7^{\prime}\right)$ are praiseworthy, or $(2) /\left(2^{*}\right)$ and $(3) /\left(3^{\prime}\right)$ are not blameworthy and $(6) /\left(6^{*}\right)$ and $(7) /\left(7^{\prime}\right)$ are not praiseworthy. Either way in order to offer a complete and consistent assessment of $(2) /\left(2^{*}\right),(3) /\left(3^{\prime}\right),(6) /\left(6^{*}\right)$, and $(7) /\left(7^{\prime}\right)$ it would be easier to consider either the intention or the result separately. But if one wants to follow the combined agent-cum-object perspective, the above-mentioned concerns arise.

\footnotetext{
30 Something similar appears in the following formulae: $a$ versus $e$ but also $a$ versus $b, b$ versus $f$ but also $b$ versus $a, c$ versus $g$ but also $c$ versus $d, d$ versus $h$ but also $d$ versus $c, e$ versus $a$ but also $e$ versus $f, f$ versus $b$ but also $f$ versus $e, g$ versus $c$ but also $g$ versus $h, h$ versus $d$ but also $h$ versus $g$. Although these two-part formulae are repeated twice for one part (e.g. $a$ versus $e \ldots e$ versus $a \ldots$ ), they are not repeated in both parts because the second part in each case varies (which, again, is repeated in second part but of another formula).
} 


\subsubsection{Tragic and Comic Error}

As it is all eight scenarios are a part of human drama if by drama we understand anything pervaded by the very feature of unexpectedness. However, since unexpectedness is a matter of degree, the same is valid for the eight scenarios. Accordingly, the scenarios $(2) /\left(2^{*}\right),(3) /\left(3^{\prime}\right),(6) /\left(6^{*}\right)$, and $(7) /\left(7^{\prime}\right)$ are a part of human drama to a much greater extent than (1), (4)/(4'), (5), and (8)/(8'). Now (3)/(3') and (6)/ $\left(6^{*}\right)$ look like an occurrence of tragic error because they are about the figures of the harmer and the not-helper despite themselves, while (2)/(2') and (7)/(7') look like an occurrence of comic error because they are about the figures of the not-harmer and the helper despite themselves. It is at this point, however, that the enlargement of the Table proves significant. For (3) seems more tragic-for both, i.e. for the agent as well as for the object-than (6) and (7) is more comic-for both, i.e. for the agent as well as for the object-than (2). But when (2) is duplicated by (2*) and (6) by $\left(6^{*}\right)$ the picture is markedly different because $\left(6^{*}\right)$ is more tragic-for both, i.e. for the agent as well as for the object-than (3)-and a fortiori than (6)-and (2*) is more comic-certainly for the object and probably for the agent-than (7)-and a fortiori than (2). The tragic and the comic are more forceful in view of the fact that the gap between the agent's intention and the result of her action in $\left(6^{*}\right)$ and $\left(2^{*}\right)$ is remarkably larger than in (6) and (2). If this is correct, of the two inversely eager scenarios, $\left(6^{*}\right)$ is the most tragic of all scenarios and $\left(2^{*}\right)$ is the most comic one. There is however a noticeable formal difference between $\left(6^{*}\right)$ and $\left(2^{*}\right)$ : while $\left(6^{*}\right)$ is tragic for both, the agent and the object, since they both will cry if $\left(6^{*}\right)$ happens, this is not so for $(2 *)$. It is certainly comic for the object, but it is much less so for the agent who failed to accomplish her intention. She may laugh because of her failure, as someone may laugh because of her slip after all, but this will be a different kind of laughter than the object's who will be more than delighted, especially if he learns about the agent's genuine intention of harming her.

\section{In Lieu of a Conclusion}

I departed from the assumption that the category of moral "luck" should be analyzed comprehensively and that the burden of proof to the contrary lies on the supporter of the fragmentariness thesis. To this end I developed alternative scenarios. I taken into account (i) whether the act intended or committed is not only an awful but also a heroic thing, (ii) whether the agent's intention is not only confirmed but also contradicted by the result of her action, and finally, (iii) whether the agent's intention is not only of doing something but also of not doing anything. The result is 8 scenarios for which two other additional scenarios (*) and four complementary formulations (') were added. Apart from the two much discussed distinctions between being lucky or unlucky and being successful or unsuccessful, new distinctions have been suggested: first, between the nasty and the nice scenarios, second, between the reluctant and eager as well as inversely eager ones, third, between weak and strong formulations, 
fourth, between scenarios with negatively expressed intention and scenarios with positively expressed intention, and, fifth, between tragic and comic scenarios. ${ }^{31}$

I believe that this kind of expansion is necessary to keep the category "luck" consistent, comprehensive or at least closer to comprehensiveness than it is usually done. But this is not to say that all scenarios equally affect human life: those where the result follows the agent's intention affect it in another way than those where it does not. Moreover, among the latter there are significant differences. The unsuccessful and comic is different to unsuccessful and tragic. Upon being unsuccessful comically, one may shrug one's shoulders after all and move on as if nothing has happened. But should the unsuccessful and tragic happen, this would be the most horrifying. This is so because the latter amounts to a modification for the worse both for the agent and the object (while the unsuccessful and comic is a modification for the worse, if at all, only for the agent). This may explain why-when moral "luck" is under consideration-(3)/(3') or $(6) /\left(6^{*}\right)$ come most often to the fore and are given much more attention in various analyses. For instance, because of the tragic error, regardless whether one reads his story as (3) ${ }^{32}$ or as ( $\left.3^{\prime}\right),{ }^{33}$ Oedipus killed his father and married his mother, though what he intended as soon as he was informed about his destiny was to escape it. But though he acted in the best available way, his intention and action did not prevent him from his failure. ${ }^{34}$

There is no space at this moment to explore all the consequences of all the elements presented above. However, I hope to have succeeded in presenting the full panorama of "luck" scenarios. This will, in turn, I hope, clear the way for treating the category "luck" more comprehensively and consistently. It is true that I posited that symmetry is crucial for keeping the category "luck" consistent. But I was not that dogmatic not to observe that there is no full non-formal symmetry. It may be that non-formal symmetry, unlike formal one, does not have to be full because, while the formal aspect is about our approach to the thing, the non-formal aspect reproduces the thing itself, the human condition in this case. I believe we get closer to its core when we take into consideration not moral or psychological assessment of the agent's act but rather the agent's value dependent, true as it seems, on unexpectedness. The moral is that if some aspect of human condition is denoted by tragic error, another one is denoted by comic error. At this stage of analysis it seems that they should be considered equally important if only the category of moral "luck" is reasonably used. Yet there is more and apart from the nasty/nice divide there are various kinds and shades of moral "luck" on each side.

\footnotetext{
31 Note that not all comic situations are the effect of an error. Peter Sellers in the "Pink Panther" films intends to catch the criminal, performs it-to believe his entourage-badly and ignorantly, and yet the result of his action follows (or coincides) with his intention. There is no error and mistake is on the part of his entourage. A different case is Pierre Richard in "Knock on Wood" since he completes unknowingly the plan otherwise unknown to him: his doing is neither erroneous nor correct insofar as he is not aware of any link between his doing and the purpose that is conceived by his entourage.

32 Maybe Freud (1913).

33 Very probably Miller (1998).

34 One may say that his adoptive parents are to blamed: had they told him about his story, he would come back to Corinth after his visit to the Oracle of Apollo, knowing who indexically was his father and his mother.
} 
Acknowledgements This paper has been inspired by a presentation given at XXVIII World Congress of IVR, Lisbon (2017). I would like to thank the audience as well as anonymous reviewers for their helpful comments and suggestions.

Open Access This article is licensed under a Creative Commons Attribution 4.0 International License, which permits use, sharing, adaptation, distribution and reproduction in any medium or format, as long as you give appropriate credit to the original author(s) and the source, provide a link to the Creative Commons licence, and indicate if changes were made. The images or other third party material in this article are included in the article's Creative Commons licence, unless indicated otherwise in a credit line to the material. If material is not included in the article's Creative Commons licence and your intended use is not permitted by statutory regulation or exceeds the permitted use, you will need to obtain permission directly from the copyright holder. To view a copy of this licence, visit http://creativecommons.org/licen ses/by/4.0/.

\section{References}

Aristotle (1894) Ethica Nicomachea, (ed) J. Bywater. Clarendon Press, Oxford

Church IM, Hartman RJ (eds) (2019) The Routledge handbook of the philosophy and psychology of luck. Routledge, New York London

Enoch D (2019) Playing the hand you're dealt: how moral luck is different from morally significant plain luck (and probably doesn't exist). Midwest Stud Philos 43:1-14

Freud S (1913) The interpretation of dreams (trans: Brill AA). G. Allen \& Co., New York

Hartman RJ (2018) Moral luck and the unfairness of morality. Philos Stud 176(2019):3179-3197

Hartman RJ (2019) In defense of moral luck: why luck often affects praiseworthiness and blameworthiness. Routledge, London

Latus A (no date) Moral luck. In: The internet encyclopedia of philosophy. Available at: https://www.iep. utm.edu/moralluc/, retrieved on June 28,2020

Miller A (1998) Thou shalt not be aware: society's betrayal of the child (trans: Hannum H, Hannum H). Noonday Press, New York

Nagel T (1976) Moral luck. Proc Aristot Soc Suppl Vol 50:115-135

Nagel T (1979) Moral luck. Nagel T (1979) Mortal questions. Cambridge University Press, Cambridge, pp 24-38

Nelkin DK (2019). Moral luck. In: The Stanford encyclopedia of philosophy, Zalta EN (ed) EN. Available at: https://plato.stanford.edu/entries/moral-luck/, retrieved on Apr. 11, 2020

Richards N (1986) Luck and desert. Mind 95:198-209

Sartorio C (2019) Kinds of moral luck. In: Church IM, Hartman RJ (eds) The Routledge handbook of the philosophy and psychology of luck. Routledge, pp 206-215

Scheler M (1973) Formalism in ethics and non-formal ethics of values. A new attempt toward the foundation of an ethical personalism (trans: Frings MS, Funk RL). Northwestern University Press, Evanston, Il

Stone A (2009). Man who killed his wife while sleeping goes free. In: Independent, Nov. 21. Available at: http://www.independent.co.uk/news/uk/crime/man-who-killed-his-wife-while-sleeping-goes-free1824945.html, retrieved on Apr. 20, 2017

Williams B (1976) Moral luck. Proc Aristot Soc Suppl Vol 50:137-151

Publisher's Note Springer Nature remains neutral with regard to jurisdictional claims in published maps and institutional affiliations. 